Boletin Mexicano de Derecho Comparado
Boletín Mexicano de Derecho Comparado, ISSN (Versión impresa): 0041-8633 bmdc@servidor.unam.mx Universidad Nacional Autónoma de México México

¿Cómo citar? | Número completo | Más información del artículo I Página de la revista

\title{
www.redalyc.org
}

Proyecto académico sin fines de lucro, desarrollado bajo la iniciativa de acceso abierto 
Esta revista forma parte del acervo de la Biblioteca Jurídica Virtual del Instituto de Investigaciones Jurídicas de la UNAM www.juridicas.unam.mx

http://biblio.juridicas.unam.mx

\section{LA SUMISIÓN DEL PODER PÚBLICO AL DEREGHO EN EL CIVIL LAW Y EN EL COMMON LAW: ESTADO DE DERECHO, RULE OF LAWY SU EXPANSIÓN AL ÁMBITO INTERNACIONAL* THE SUBMISSION OF THE PUBLIC POWER TO THE LAW IN THE CIVIL LAW AND THE COMMON LAW TRADITIONS: RECHTSSTAAT AND RULE OF LAW. CAN BE EXTRAPOLATED TO THE INTERNATIONAL LEVEL?}

\section{César Villegas DelgadO**}

RESUMEN: Considerados generalmente como sinónimos, Rule of Law y Rechsstaat son diferentes. Hay diferencias sustanciales entre estas dos instituciones legales que debemos distinguir rigurosamente. La idea de la sumisión del poder público al derecho expresada a través de ambas construcciones teóricas ha trascendido las fronteras estatales y se ha instalado plenamente en el ámbito internacional. Para algunos autores, la raíz de la aplicación del principio de Rule of Law en las relaciones interestatales dentro de la sociedad internacional podría remontarse al siglo XVIII. Sin embargo, fue hasta hace unos pocos años que el análisis del Rule of Law, desde el estricto punto de vista internacional, comenzó a despegar. En este artículo el autor analiza las diferencias entre el Recgsstaat y el Rule of Law con el fin de estudiar la extensión de estos conceptos y cómo se podrían aplicar para resaltar la preeminencia de la ley a nivel internacional.

Palabras clave: tradición jurídica conti- Keywords: Civil Law, Common Law, Rule of nental, tradición jurídica anglosajona, Estado de derecho, Estado de derecho internacional, preeminencia del derecho.
ABSTRACT: Generally regarded as synonyms, the Rule of Law and the Rechsstaat are different. There are between the two legal institutions substantial differences that we must distinguish rigorously. The idea of the public power submission to the law - expressed through both theoretical constructions - has gone beyond the State borders and, progressively, made its way into international scenario. For some authors, the root for the application of the principle of the Rule of Law to interstate relationships, within international society, could date back to the XVIII century. However, it was until a few years ago that the Rule of Law analysis, from a strictly international point of view, started to take off. In this article the author analyzes the differences between the Rechsstaat and the Rule of Law in order to study the extension of these conceptions and how it could be applied to highlight the preeminence of law at international level.

* Artículo recibido el 9 de agosto de 2012 y aceptado para su publicación el 28 de febrero de 2013.

** Profesor de Derecho internacional público y relaciones internacionales de la Universidad de Sevilla. Licenciado y doctor en derecho. Máster en Jurisdicción Penal Internacional. E-mailcvillegas@us.es

Boletín Mexicano de Derecho Comparado, nueva serie, año XLVI, núm. 137, mayo-agosto de 2013, pp. 713-746.

D.R.C 2013. UNAM, Instituto de Investigaciones Jurídicas. 
Esta revista forma parte del acervo de la Biblioteca Jurídica Virtual del Instituto de Investigaciones Jurídicas de la UNAM

SUMARIO: I. Introducción. II. La sumisión del poder público al derecho en la tradición jurídica continental: el Estado de derecho o Rechtsstaat. III. La sumisión del poder público al derecho en la tradición jurídica del Common Law: el Rule of Law. IV. Estado de derecho, Rule of Law y la diferencia entre los modelos clásicos.

V. Su expansión al ámbito internacional. VI. Conclusiones. VII. Bibliografia.

\section{INTRODUCGIÓN}

La lucha por promover la sumisión del poder público al derecho, a lo largo de la historia, ha constituido - y constituye - una batalla que se ha librado en dos escenarios sustancialmente distintos: uno interno y otro internacional.

En el plano interno, el sometimiento del poder público al derecho ha sido objeto de estudio en las distintas tradiciones jurídicas existentes en el mundo. Dentro del Civil Law y el Common Law —es decir, dentro de las dos principales tradiciones jurídicas de Occidente en las que vamos a centrar nuestra atención-, la idea de la sumisión del poder público al derecho se ha expresado a través del Estado de derecho y del Rule of Law, respectivamente. A pesar de que, generalmente, suelen considerarse ambos términos como sinónimos — lo que ha creado cierta confusión—, debemos señalar que entre ambas instituciones jurídicas existen apreciables diferencias que es preciso distinguir. Fuera del ámbito jurídico estatal interno, dicha confusión sería aún mayor.

En efecto, y al margen de las diferencias sustanciales que existen entre el medio social interno y el internacional, se ha asumido la idea de que determinados principios liberales derivados de la Ilustración, como el Estado de derecho, pueden ser utilizados en el ámbito internacional tal como han sido aplicados en el plano interno. Como consecuencia de lo anterior, es posible constatar en la doctrina el empleo de términos tales como: "Estado de derecho internacional", "International Rule of Law" o "Rule of Law among Nations" para hacer referencia a la sumisión del poder público al derecho en el plano internacional, pero sin que exista consenso alguno en torno a su alcance y contenido.

En este contexto, procederemos a analizar, por un lado, las diferencias que existen entre el Estado de derecho continental y el Rule of Law anglosajón para, posteriormente, cuestionarnos si sería posible extrapolar tanto el Estado de derecho como el Rule of Law al ámbito internacional - tal 
Esta revista forma parte del acervo de la Biblioteca Jurídica Virtual del Instituto de Investigaciones Jurídicas de la UNAM

como han sido aplicados en el plano interno - con el objeto de subrayar la sumisión del poder público al derecho. De ser así, habría que plantearse si tendrían el mismo significado y alcance que a la luz del orden jurídico estatal interno.

\section{LA SUMISIÓN DEL PODER PÚBLICO AL DERECHO EN LA TRADICIÓN JURÍDICA CONTINENTAL: EL ESTADO DE DERECHO O RECHTSSTAAT}

Dentro de la tradición jurídica del Civil Law o continental, la idea de la sumisión del poder al derecho estuvo ligada a una determinada fase histórica de la evolución del Estado absoluto ${ }^{1}$ al Estado liberal. ${ }^{2}$ Dentro de esa etapa, tanto las ideas antiabsolutistas derivadas del Segundo tratado de Locke ${ }^{3}$ como la teoría de la división de poderes expresada por Montesquieu en El espiritu de las leyes, ejercieron un papel determinante. En efecto, estas ideas constituirían la base de una construcción doctrinal que propugnaba la autolimitación del poder a través de la observancia de la ley, es decir, el Estado de derecho o Rechtsstaat. ${ }^{4}$

La elaboración del término Estado de derecho o Rechtsstaat y la descripción de la realidad a la que alude fueron el resultado de un largo proceso, que hunde sus raíces en épocas pasadas. ${ }^{5}$

$\mathrm{Al}$ menos desde la perspectiva europeo-occidental, el origen de la noción (no de la expresión, que no llegó a utilizar) suele ser atribuido a Kant. En su pensamiento se depura la idea de contrato social, ${ }^{6}$ no como un instrumento al servicio de una finalidad extrínseca, sino como fundamento

1 Véase, Anderson, Perry, El Estado absolutista, 6a. ed., México, Siglo XXI, 1990.

2 Schwartz, Pedro, "El Estado liberal", Estudios públicos, Madrid, núm. 27, 1987, pp. 47 y ss.

3 Sobre el tema véase Locke, John, Segundo tratado sobre el gobierno civil: un ensayo acerca del verdadero origen, alcance y fin del gobierno civil, Madrid, Alianza, 2004.

4 Stern, Klaus, Der rechtsstaat, Krefeld, Scherpe, 1971, p. 46.

5 En este sentido, autores como Scheuner se refieren al pensamiento y a las instituciones anteriores al siglo XIX simplemente como precedentes de la idea decimonónica del Estado de derecho. En este sentido, véase Scheuner, Ulrich, "Die neuere entwicklung des rechtsstaats", en Forsthoff, Rechtsstaatlichkeit und sozialstaatlichkeit, Darmstadt, Buchges, 1968, p. 469.

6 Rubio Llorente, Francisco, "Derechos fundamentales, derechos humanos y Estado de derecho", Fundamentos: cuadernos monográficos de teoría del Estado, derecho público e historia constitucional, Oviedo, núm. 4, 2004, p. 217.

D.R.C 2013. UNAM, Instituto de Investigaciones Jurídicas, Boletín Mexicano de Derecho Comparado, núm. 137, pp. 713-746. 
Esta revista forma parte del acervo de la Biblioteca Jurídica Virtual del Instituto de Investigaciones Jurídicas de la UNAM

del derecho de los hombres a vivir bajo leyes respaldadas por la coacción pública, merced a las cuales se da a cada uno lo que le corresponde y se le asegura frente al ataque de los demás. Con él se logra, en definitiva, una sociedad sometida al derecho, donde la limitación de la libertad de cada uno condiciona su coexistencia con las libertades de los demás, en la medida en que esto sea posible según la ley general. El contrato social es el acto fundacional del Estado, cuya finalidad es, en suma, la creación del derecho (positivo), el establecimiento y aplicación de normas que aseguran la libertad de todos los miembros de la sociedad en cuanto hombres y la igualdad entre ellos. ${ }^{7}$

No obstante, y al margen de los antecedentes que podríamos identificar en la filosofia kantiana, es necesario señalar que no sería sino hasta principios del siglo XIX cuando el Estado de derecho o Rechtsstaat se estructuraría por vez primera como un concepto dentro de la ciencia jurídica alemana ${ }^{8}$ - aunque la idea, para algunos autores como Otto Mayer, no fue exclusiva del pensamiento germánico-.${ }^{9}$

En efecto, la expresión Rechtsstaat, como concepto debidamente estructurado, nació en Alemania, pasando de allí a la doctrina de otros países. ${ }^{10}$ En este sentido, la traducción literal del Rechtsstaat pasaría al francés como État de droit, ${ }^{11}$ y al español como Estado de derecho. ${ }^{12}$ En virtud de lo anterior, tomaremos como punto central de referencia la doctrina alemana para elaborar un análisis retrospectivo en torno a la institución del Estado de derecho.

Desde esta perspectiva, la paternidad del término Rechtsstaat o Estado de derecho suele ser atribuida a Robert Von Mohl, de quien se afirma haberlo utilizado, por primera vez, en su obra Staatsrecht des Königsreichs Würtemberg, publicada en 1829 y, asimismo, haberlo incluido en el título

7 Ibidem, p. 218.

8 Lucas Verdú, Pablo, La lucha por el Estado de derecho, Bolonia, Real Colegio de España, 1975, p. 20.

9 Véase Mayer, Otto, Deutsches verwaltungsrecht, Berlín, Humblot, 1924.

10 En este sentido, véase García Pelayo, Manuel, Las transformaciones del Estado contemporáneo, Madrid, Alianza, 1996, p. 224.

$11 \mathrm{Al}$ respecto, véanse, Chevalier, Jacques, L’État de droit, París, Montchrestien, 1994; Heuschling, Luc, État de droit, Rechtsstaat, Rule of Law, París, Dalloz, 2002.

12 Pereira Menaut, Carlos, Rule of Law o Estado de derecho, Madrid, Marcial Pons, 2003, p. 34 .

D.R.C 2013. UNAM, Instituto de Investigaciones Jurídicas,

Boletín Mexicano de Derecho Comparado, núm. 137, pp. 713-746. 
Esta revista forma parte del acervo de la Biblioteca Jurídica Virtual del Instituto de Investigaciones Jurídicas de la UNAM

de una obra posterior, Die deutsche Polizeiwissenschaft nach den Grundsätzen des Rechtsstaates, que vio la luz en $1833 .{ }^{13}$

Para este autor, el Estado de derecho o Rechtsstaat no representó una nueva fórmula política, sino una peculiar forma de Estado (Staatsgattung), esto es, un tipo de Estado con unas exigencias de contenido o materiales que se cifraban, concretamente, en: a) la necesidad de una organización y regulación de la actividad estatal guiada por principios racionales; b) el rechazo de cualquier tipo de transpersonalismo en la definición de los objetivos del poder. El Estado no es una institución puesta al servicio de fines trascendentes de carácter divino, ni de los intereses de quienes gobiernan, sino que se encuentra en función del beneficio de todos los individuos que lo integran; c) limitación de las tareas del Estado a la garantía de la libertad, la seguridad y la propiedad de sus ciudadanos a través de la ley, concebida como norma general emanada de los representantes de la voluntad popular. ${ }^{14}$

Aunque el concepto de Estado de derecho acuñado por Von Mohl es un concepto que cabría llamar teleológico - puesto que es la finalidad perseguida por el Estado la que determina su forma-, hay en él, junto con elementos nuevos, una mayor atención a las exigencias puramente formales que la realización del derecho implica para la estructura y el funcionamiento del Estado. El hombre no es visto sólo desde la perspectiva de la razón, ${ }^{15}$ sino también desde la realidad material. En consecuencia, el Estado de derecho, para serlo, ha de llevar a cabo, junto a la actividad puramente jurídica de creación y aplicación de normas, una actividad administrativa, prestacional. Aunque para algún sector de la doctrina ${ }^{16}$ esta concepción - que todavía ve en la realización de la libertad y la igualdad el fin necesario del derecho- no significa en modo alguno una formalización del concepto (e incluso permite considerar a Von Mohl como un

13 Sobre el origen del Estado de derecho dentro de la ciencia jurídica alemana véase Böckenförde, Ernst, Estudios sobre el Estado de derecho y la democracia, Madrid, Trotta, 2000.

14 Pérez Luño, Enrique, Derechos humanos, Estado de derecho y Constitución, 8a. ed., Madrid, Tecnos, 2003, p. 220.

15 Mohl, Robert, Die deutsche polizeiweissenschaft nach den grundsätzen des rechtsstaates, Tübingen, Laupp, 1833, p. 10.

16 Böckenförde, Ernst, Recht, staat, freiheit. studien zur rechtsphilosophie, staatstheorie und verfassungsgeschichte, Suhrkamp Frankfurt am Main, Verlag, 1992.

D.R.C 2013. UNAM, Instituto de Investigaciones Jurídicas, Boletín Mexicano de Derecho Comparado, núm. 137, pp. 713-746. 
Esta revista forma parte del acervo de la Biblioteca Jurídica Virtual del Instituto de Investigaciones Jurídicas de la UNAM

precursor del Estado social), en ella se encierra ya, para otros, ${ }^{17}$ el germen de una evolución que reduce la idea de Estado de derecho a pura forma, cuyo significado se agota en el sometimiento de la administración a la ley, en tanto que el contenido de la ley misma, e incluso su vinculación a la voluntad pública, dejan de ser relevantes.

Sin entrar en esa polémica, cabe señalar que el primer paso hacia la pura formalización del concepto de Estado de derecho se produce en 1837, de forma paradójica, con la obra Die Philosophie des Rechts, de Stahl, un autor que se inscribe en la corriente más conservadora de la derecha hegeliana e, ideológicamente, se sitúa en las antípodas de Von Mohl. ${ }^{18}$ Pese a ello, asume la idea típicamente liberal del Estado de derecho y ofrece de éste una definición que constituirá el punto de partida obligado para todo el pensamiento posterior. En este sentido, señala que:

El Estado ha de ser Estado de derecho; ésta es la consigna y, en verdad, también la tendencia de los nuevos tiempos. Ha de utilizar el derecho para determinar con precisión y asegurar de modo inquebrantable, tanto las vías y los límites de su actividad como la esfera de libertades de sus ciudadanos. No ha de llevar la realización estatal más allá de lo que es propio de la esfera jurídica, esto es, reducir la coacción a lo estrictamente indispensable. Éste es el concepto de Estado de derecho, no que el Estado se limite a la aplicación del ordenamiento, o simplemente a la protección plena de los derechos individuales. El Estado de derecho no hace referencia a la finalidad y el contenido del Estado, sino sólo al modo y manera de realizarlos. ${ }^{19}$

A pesar de que el autor utiliza una concepción del derecho no exenta de consecuencias materiales, afirma rotundamente que la noción de Estado de derecho no hace referencia a los fines del Estado, sino sólo al modo que éste tiene de realizarlos, es decir, a la forma. ${ }^{20}$ Desde esta perspectiva, los elementos materiales, los derechos humanos, quedan latentes como

17 Maus, Ingeborg, "Entwicklung und dem funktionswandel der theorie des bürgerlichen rechtsstaates", en Tohidipur (coord.), Der bürgerlichen rechtsstaat, Frankfurt, Suhrkamp, 1978.

18 Sobre la obra de Stahl, véase Volz, Otto, Christentum und positivismus. Die grundlagen der rechts- und staatsauffassung Friedrich Fulius Stahls, Tübingen, J. C. B. Mohr, 1951.

19 Stahl, Friedrich Julius, Philosophie des rechts, Bd. II, rechts und rtaatslehere auf der grundlage christlichen weltanschauung, Hildesheim, Georg Olms, 1963, p. 137.

20 Rubio Llorente, Francisco, "Derechos fundamentales...", cit., nota 6, p. 222.

D.R.C 2013. UNAM, Instituto de Investigaciones Jurídicas,

Boletín Mexicano de Derecho Comparado, núm. 137, pp. 713-746. 
Esta revista forma parte del acervo de la Biblioteca Jurídica Virtual del Instituto de Investigaciones Jurídicas de la UNAM

elementos de una estructura puramente formal con la que se identifica el derecho. Estado de derecho es el que acomoda a derecho la intromisión del poder en la libertad o la propiedad de los individuos, pero el derecho es pura forma, el lenguaje necesario del poder, y no un límite material para su actuación.

En definitiva, la principal consecuencia que se deriva de la idea del Estado de derecho es la que afecta a la estructura estatal. El Estado de derecho exige una separación de poderes, con una distinción neta entre la función legislativa, la ejecutiva y la judicial. La creación del derecho queda reservada exclusivamente a la ley, pero la identificación de ésta con la voluntad pública de la teoría kantiana se difumina poco a poco. Incluso la forma necesaria que inicialmente se postula para la ley, la de que ésta se produzca como norma general y abstracta, se va debilitando poco a poco y, a partir de Laband, como es sabido, el único criterio distintivo de la ley, el rasgo al que se anuda su fuerza específica, será su origen. ${ }^{21}$

La sujeción del Estado al derecho significa simplemente sujeción del ejecutivo a la norma aprobada por el Parlamento, sean cuales fueren su forma y su contenido. Pero es una sujeción cada vez más acentuada. El largo debate sobre la reserva de ley, la delimitación del ámbito en el que la actuación de la administración requiere una previa decisión del legislador se va ampliando. La fórmula se mantiene durante largo tiempo sin experimentar apenas cambios; la ley es necesaria para la injerencia de la administración en la libertad y la propiedad de los individuos, es decir, en sus derechos. El modo de entenderla evoluciona, sin embargo, con el tiempo y la idea de la vinculación meramente negativa de la administración a la ley va siendo sustituida por la de la vinculación positiva. En este sentido, la Administración no puede hacer todo lo que la ley no le impide, sino sólo aquello para lo que la ley le habilita. ${ }^{22}$

Junto con este proceso de ampliación del ámbito de la actividad administrativa sujeta a la ley, y naturalmente en estrecha conexión con él, discurre el de afirmación del control judicial de dicha actividad y el reconocimiento de la responsabilidad patrimonial de la administración.

21 Sobre el tema véase Laband, Paul, Staatsrecht des deutschen reiches, Tübingen, J. C. B. Mhor, 1901, t. IV.

22 Scheuner, Ulrich, "Die neuere...", cit., nota 5, p. 481. 
Esta revista forma parte del acervo de la Biblioteca Jurídica Virtual del Instituto de Investigaciones Jurídicas de la UNAM

Al final de esta evolución, el Estado de derecho significa, según un texto de Richard Thoma:

Omnipotencia de la ley, pero sólo de una ley que deje espacio a la libre iniciativa; responsabilidad jurídica del Estado y de los funcionarios por la violación culpable de los límites impuestos por la ley; garantía, mediante tribunales administrativos y autoridades independientes, frente a la utilización inadecuada o partidista de la ley; finalmente: creación de un derecho público minucioso mediante la reelaboración jurídicamente avanzada de una legislación que hasta ahora ha estado excesivamente dominada sólo por consideraciones políticas. ${ }^{23}$

Desde esta perspectiva, ya no hay rastro de la idea que vinculaba el Estado a la realización de los derechos humanos. El legislador omnipotente goza de plena libertad para definir el bien común y perseguirlo por los medios que considere adecuados, sin verse limitado por supuestos derechos o libertades garantizados por un derecho superior. ${ }^{24}$ Tampoco de los derechos fundamentales queda gran cosa en ese Estado de derecho administrativo bien ordenado. ${ }^{25}$ Sólo esa oscura alusión a la necesidad de que la ley que sujeta a la administración deje espacio a la "libre iniciativa" del individuo sugiere la existencia de alguna limitación material, sustantiva, al poder del legislador.

Pero se trata en todo caso de una necesidad política, no jurídica. ${ }^{26} \mathrm{El}$ legislador no se enfrenta a derechos que haya de respetar, pues los que la constitución enuncia o garantiza no tienen otro contenido que el que el propio legislador les atribuye y quizás ni siquiera para proteger la libertad del sujeto, sino en atención a otros fines. De la idea de que el Estado de derecho tiene como finalidad la creación del derecho positivo para hacer

23 Thoma, Richard, "Rechtsstaatsidee und verwaltungsrechtswissenschaft", Jahrbuchs des öffentlichen Rechts der Gegenwart, Tübingen, J. C. B. Mohr, 1910, vol. 4, p. 214.

24 Para Scheuner, el Estado de derecho implica la existencia de un poder legislativo ilimitado que en interés del bien común puede imponer nuevas ordenaciones de la vida en común, por encima de todos los derechos, libertades y situaciones establecidas. Véase Scheuner, Ulrich, "Die neuere...", cit., nota 5, p. 201.

25 Sobre el tema, véase Mayer, Otto, Deutsches..., cit., nota 9, p. 340.

26 Stein, Torsten, "Estado de derecho, poder público y legitimación desde la perspectiva alemana", Working Papers, Barcelona, Institut de Ciencies Politiques i Socials, núm. 88, 1994, p. 17.

D.R.C 2013. UNAM, Instituto de Investigaciones Jurídicas,

Boletín Mexicano de Derecho Comparado, núm. 137, pp. 713-746. 
Esta revista forma parte del acervo de la Biblioteca Jurídica Virtual del Instituto de Investigaciones Jurídicas de la UNAM

realidad los derechos humanos y está limitado por unos derechos preexistentes cuya positivización es condición inexcusable de la legitimidad del poder, se ha pasado a una situación en la que, autores como Jellinek, se han opuesto a quienes ven en los derechos individuales simples "derechos reflejo". ${ }^{27}$

Para el profesor Pérez Luño, la teoría del Estado de derecho forjada por Mayer, Thoma, Laband y Jellinek que alcanza pleno desarrollo, en su orientación positivista-formalista, con la obra de Kelsen, constituye la expresión más acabada del Estado liberal de derecho. ${ }^{28}$

Para este autor, los rasgos definitorios del Estado liberal de derecho fueron: a) una aparente despolitización del Estado que, lejos de proponerse la realización de fines políticos propios, aparece como un mero instrumento neutro y disponible para asegurar el laissez faire. Para ello se consuma la fractura entre sociedad y Estado, al independizar la organización y reproducción del poder político de cualquier conexión con la sociedad. Estos presupuestos se traducen, en la práctica, en la cobertura ideológica de los intereses de la burguesía. El Estado liberal de derecho funciona como un Estado al servicio de la burguesía para lo que dificulta el ejercicio del derecho de asociación, abandona el mercado a los económicamente poderosos y reconoce una libertad e igualdad en el plano formal, que no tiene correspondencia en el social y económico; y, b) tendencia hacia la identificación del concepto de Estado de derecho con el principio de legalidad, lo que implica el sometimiento de la Administración a la ley, así como la posibilidad del control jurisdiccional de sus actos. Ahora bien, la supresión de cualquier referencia al contenido material de la legalidad termina por conducir a una identificación absoluta entre legalidad y Estado de derecho o, lo que es igual, entre el Estado y el derecho. ${ }^{29}$

De lo anterior cabría concluir que, de acuerdo con Kelsen y desde un punto de vista formal, todo Estado, por el mero hecho de serlo, sería un

27 Dicho autor, se opone tanto a quienes identifican los derechos públicos subjetivos con derechos privados, como a quienes niegan su posibilidad porque en el ámbito del derecho público sólo caben los "derechos reflejo", es decir, aquellos que la norma objetiva concede en atención a fines generales, no para respetar unos (imposibles) derechos de quienes se benefician del "reflejo". Véase, Jellinek, Georg, System der subjektiven öffentlichen rechte, Tübingen, Verlag, 1979; Cfr. Jellinek, Georg, Allgemeine staatslehre, Berlín, Springer, 1922.

28 Pérez Luño, Enrique, Derechos humanos..., cit., nota 14, p. 222.

29 Ibidem, p. 223. 
Esta revista forma parte del acervo de la Biblioteca Jurídica Virtual del Instituto de Investigaciones Jurídicas de la UNAM

Estado de derecho. ${ }^{30}$ Esta afirmación contraría, como es sabido, lo que en reiteradas ocasiones ha afirmado el profesor Elías Díaz, en el sentido de que no todo Estado sería un Estado de derecho. ${ }^{31}$

Aunque este modo puramente formal de concebir al Estado de derecho, que fue el que se impuso en la práctica de los Estados continentales europeos del siglo XIX, venía siendo objeto de críticas desde mucho tiempo atrás, su derrumbamiento no se produciría hasta el término de la Primera Guerra Mundial, con la quiebra en Alemania de la Monarquía Constitucional. Con la instauración de un régimen democrático, y la consiguiente presencia en el Reichstag de fuerzas políticas que ponían en cuestión el orden social y económico hasta entonces imperante, comenzaría a cuestionarse también la racionalidad de la ley, quebrantándose la fe en el legislador. ${ }^{32}$

En este sentido, empezaría a consolidarse la idea de que determinados derechos se encontraban por encima de la ley. $\mathrm{Al}$ introducirse la vinculación del legislador a ellos - situación que sólo había dado fruto fuera de Alemania, con la introducción de un innovador sistema de jurisdicción constitucional en Austria, la antigua Checoslovaquia ${ }^{33}$ y, más tarde, en España-,${ }^{34}$ se daría paso a una concepción material del Estado de derecho. Desde un punto de vista material, el Estado de derecho pasó a expre-

30 Kelsen, Hans, Allgemeine Staatslehre, Berlín, Springer, 1925, pp. 91 y 100.

31 Para este autor, la existencia de un orden jurídico, de un sistema de legalidad, no autoriza a hablar sin más de un Estado de derecho. Designar como tal a todo Estado por el simple hecho de que se sirve de un sistema normativo jurídico constituye una imprecisión conceptual y real que sólo lleva al confusionismo. Adoptando como punto de partida la tesis de que el Estado de derecho es el Estado sometido al derecho, es decir, el Estado cuyo poder y actividad se hallan regulados y controlados por la ley, dicho autor señala que el Estado de derecho consiste, fundamentalmente, en el imperio de la ley. El Estado de derecho, como Estado con poder regulado y limitado por la ley, se contrapone a cualquier forma de Estado absoluto y totalitario, como Estado con poder ilimitado. Véase Díaz, Elías, Estado de derecho y sociedad democrática, Madrid, Taurus, 1998, p. 29.

32 Rubio Llorente, Francisco, "Derechos fundamentales...", cit., nota 6, p. 225.

33 Para un estudio en torno a las jurisdicciones constitucionales de Austria y la antigua Checoslovaquia véase García Pelayo, Manuel, Derecho constitucional comparado, Madrid, Alianza, 1999, p. 636.

34 Sobre el tema, véase Caamaño Domínguez, Francisco, furisdicción y procesos constitucionales, Madrid, McGraw-Hill, 1997; Fernández Segado, Francisco, La jurisdicción constitucional en España, Madrid, Dykinson, 1984; Rubio Llorente, Francisco et al., Estudios sobre jurisdicción constitucional, Madrid, McGraw-Hill, 1998.

D.R.C 2013. UNAM, Instituto de Investigaciones Jurídicas,

Boletín Mexicano de Derecho Comparado, núm. 137, pp. 713-746. 
Esta revista forma parte del acervo de la Biblioteca Jurídica Virtual del Instituto de Investigaciones Jurídicas de la UNAM

sar no sólo la sumisión del poder al derecho, sino también la sumisión del legislador a un orden superior de normas.

\section{El Estado de derecho formal y el Estado de derecho material}

Con la expresión Estado de derecho, como asegura el profesor Ferrajoli, se designan habitualmente, en el uso corriente, dos realidades diferentes que es oportuno distinguir con rigor.

En sentido lato, débil o formal - al que el autor denomina Estado legislativo de derecho-, la expresión designa a cualquier ordenamiento en el que los poderes públicos son conferidos por la ley y ejercitados en las formas y con los procedimientos legalmente establecidos. Desde esta perspectiva, serían Estados de derecho todos los ordenamientos jurídicos modernos, incluso los más antiliberales, en los que los poderes públicos tienen una fuente y una forma legal. En un segundo sentido, fuerte, material o sustancial —al que el autor denomina Estado constitucional de derecho-, se refiere, en cambio, sólo a aquellos ordenamientos en los que los poderes públicos están, además, sujetos a la ley no sólo en lo relativo a las formas, sino también a los contenidos. En este significado más restringido, que es el que defiende dicho autor, se ubicarían únicamente aquellos ordenamientos en los que todos los poderes, incluido el legislativo, están vinculados al respeto de principios sustanciales, establecidos por las normas constitucionales, como la división de poderes y los derechos fundamentales. ${ }^{35}$

El sentido formal de la institución del Estado de derecho ha sido defendido por autores como Fromont, que lo concibe como aquella idea según la cual la acción del Estado no es legítima más que si obedece al derecho, es decir, a un conjunto de normas preestablecidas. ${ }^{36}$ Como podemos advertir, para este autor la legalidad de la actuación del poder público del Estado depende, esencialmente, de la observancia de un determinado cuerpo normativo, con la condición de que haya sido previa y formalmente establecido. Esta posición formal, no prejuzgaría respecto al hecho

35 Sobre este punto, véase Ferrajoli, Luigi, "Pasado y futuro del Estado de derecho" en Carbonell, Miguel y Orozco, Wistano (coords.), Estado de derecho, concepto, fundamentos y democratización en América Latina, México, Siglo XXI- UNAM, 2002, pp. 187 y 188.

36 Fromont, Michel, "République fédérale d'Allemagne. L'État de droit", Revue de Droit Public, núm. 5, 1984, pp. 1203-1226.

D.R.C 2013. UNAM, Instituto de Investigaciones Jurídicas, Boletín Mexicano de Derecho Comparado, núm. 137, pp. 713-746. 
Esta revista forma parte del acervo de la Biblioteca Jurídica Virtual del Instituto de Investigaciones Jurídicas de la UNAM

de que el marco jurídico que rige la acción del Estado haya sido legítimamente establecido. En este sentido, el Estado de derecho será meramente formal cuando los típicos elementos formales del derecho, es decir procedimientos y competencias resolutorias, reglamenten la vida pública, pero sin estar planteada la exigencia de una orientación de su contenido según un orden superior de normas. ${ }^{37}$

Por otra parte, juristas como el profesor Pérez Luño no parecen compartir la idea formal del Estado de derecho, y sostienen que se trata no sólo de un Estado de legalidad formal, sino de aquel Estado en el que la legalidad se funda en la soberanía popular y se dirige a la tutela de los derechos fundamentales. El Estado de derecho es, por tanto, una expresión de legalidad política. ${ }^{38}$

Estas consideraciones se ajustarían, precisamente, al sentido material o sustancial del Estado de derecho, toda vez que, como menciona este último autor, la legalidad a la que se encuentra sometido el poder público dentro de un Estado de derecho está orientada por un orden superior de normas, fundamentadas sobre la base de la soberanía popular y la protección de los derechos fundamentales. Por tanto, se considerará un Estado de derecho sustancial o material aquel Estado que también garantice el compromiso del contenido de la legislación con normas superiores y lo asegure con una Constitución que normativice los derechos fundamentales del individuo mediante una legislación subordinada a esa Constitución. ${ }^{39}$

Ahora bien, y continuando con la sistemática planteada en la introducción del presente trabajo, pasaremos a examinar la configuración que la sumisión del poder público al derecho ha experimentado en el seno de la tradición jurídica anglosajona o del Common Law.

\section{LA SUMISIÓN DEL PODER PÚBLICO AL DERECHO \\ EN LA TRADICIÓN JURÍDICA DEL COMMON LAW: EL RULE OF LAW}

Dentro de la tradición jurídica del Common Law, la sumisión del poder público al derecho tuvo sus orígenes en la idea medieval de la primacía

37 Stein, Torsten, "Estado de derecho...", cit., nota 26, p. 11.

38 Pérez Luño, Enrique, La seguridad jurídica, 2a. ed., Barcelona, Ariel, 1994, p. 59.

39 Stein, Torsten, "Estado de derecho...", cit., nota 26, p. 11 y ss. 
Esta revista forma parte del acervo de la Biblioteca Jurídica Virtual del Instituto de Investigaciones Jurídicas de la UNAM

de la ley, en virtud de la cual todos los poderes públicos, incluido el Rey, debían someterse al derecho. ${ }^{40}$

La sumisión del rey a la ley es proclamada por Bracton, a mediados del siglo XIII, en su obra De Legibus et Consuetudinibus Angliae. ${ }^{41}$ En la misma, el autor establece una tajante separación entre el gubernatum y la jurisdictio, esto es, entre la esfera del poder o del mando, en manos del Monarca, y la esfera de la administración de justicia, de la que el Monarca formaba parte pero a la que estaba, a su vez, sometido. ${ }^{42}$ Bracton reconoce al rey de Inglaterra una absoluta libertad para aprobar y modificar las normas jurídicas necesarias para ejercer el gubernaculum, que recibían el nombre de leges, constitutiones y assisae, pero, en cambio, limita la potestad jurídica del rey en lo que concierne a la lex terrea, que sólo podía ser aprobada y derogada por el rey con el consentimiento de la curia regis. ${ }^{43}$

Este derecho pactado entre el rey y su curia se componía, minoritariamente, de normas escritas. Así ocurrió, por ejemplo, con la Carta Magna de 1215, que fue, según recuerda Maitland, el texto jurídico más relevante en la baja Edad Media inglesa y con el que comienza el statute law inglés. ${ }^{44}$ Se trataba de un contrato feudal, en virtud del cual el Rey Juan Sin Tierra se había comprometido a respetar los privilegios de los hombres libres - es decir, de todos los nobles y prelados-, obligándose a recabar su consentimiento para imponer tributos, a respetar sus propiedades y a cumplir fielmente un conjunto de garantías procesales.

Pero el derecho emanado del Rey y sus barones se componía, primordialmente, de costumbres no escritas, algunas muy antiguas, que el rey y su curia, más que aprobar, se limitaban a confirmar. A este derecho consuetudinario o Common Law se refiere Bracton cuando señala, en uno de los párrafos más conocidos e importantes de su libro, que era el derecho

40 Tamanaha, Brian, On the Rule of Law: History, Politics, Theory, Cambridge, Cambridge University Press, 2006, pp. 15 y ss.

41 Dicha obra fue redactada, posiblemente, entre 1257 y 1268. En todo caso, véase Bracton, Henry, De Legibus et Consuetudinibus Angliae, Londres, Richard Tottel, 1569.

42 McIlwain, Charles, Constitucionalismo antiguo y moderno, Madrid, Centro de Estudios Políticos y Constitucionales, 1991, p. 101.

43 Un órgano que además de ejercer funciones legislativas y ejecutivas actuaba como el Supremo Tribunal de Justicia del Reino. Sobre el tema, véase McIlwain, Charles, op. cit., nota anterior, pp. 106 y 107.

44 Maitland, Frederic, The Constitutional History of England, Cambridge, Cambridge University Press, 1908, p. 338. 
Esta revista forma parte del acervo de la Biblioteca Jurídica Virtual del Instituto de Investigaciones Jurídicas de la UNAM

quien hacía al rey y no a la inversa: ipse autem rex non debet esse sub homine sed sub deo et sub lege, quia lex facit regem. ${ }^{45}$

Dentro de este Common Law, el principio de la primacía de la ley se vería favorecido por la aparición del Parlamento. ${ }^{46}$ En efecto, en dos obras escritas entre 1470 y 1476, tituladas De Laudibus Legum Angliae y The Governance of England, Fortescue sostuvo que, mientras Inglaterra era un dominium politicum regale, Francia, su secular enemiga, era un simple dominium regale. Con lo anterior, dicho autor - que ha sido reconocido como el pensador político inglés más importante del siglo XV - resaltaba el hecho de que en Inglaterra, a diferencia de Francia, el Monarca estaba sometido al derecho que él mismo aprobaba con la participación del Parlamento. ${ }^{47}$

$\mathrm{Al}$ margen de dicho antecedente, lo cierto es que no sería hasta finales del siglo XIX cuando el Rule of Law sería estructurado como un concepto. En efecto, la formulación conceptual del Rule of Law no aparecería hasta el año 1885 dentro de la obra de Albert Venn Dicey titulada Introduction to the Study of the Law of the Constitution. ${ }^{48}$ En dicho trabajo, Dicey puso en evidencia los cambios más importantes que se habían producido, hasta esa fecha, en el modo de entender el derecho constitucional británico a causa, sobre todo, de las profundas transformaciones verificadas en el régimen jurídico e institucional del Reino Unido.

Dentro de su obra, Dicey daría tres significados distintos a dicho concepto, de tal forma que el Rule of Law:

Significaba la supremacía absoluta o predominante de la ley ordinaria contrapuesta a la influencia del poder arbitrario y excluía la existencia de la arbitrariedad de la prerrogativa y la extrema autoridad discrecional del gobierno.

Representaba, también, igualdad ante la ley o sometimiento igual de todas las clases a la ley ordinaria. Por lo tanto, el Rule of Law no contemplaba exención alguna — por parte de los funcionarios - a la obediencia de la ley

45 Bracton, Henry, On the Laws and Customs of England, Harvard University Press, 1968, vol. II, p. 33.

46 Maitland, Frederic, The Constitutional..., cit., nota 44, p. 54.

47 Sobre el tema, véase Hinton, R., "English constitutional doctrines from the fifteenth century to the seventeenth: I. english constitutional theories from Sir John Fortescue to Sir John Eliot", The English Historical Review, núm. 296, 1960, vol. 75, pp.335-351.

48 Dicey, Albert Venn, Introduction to the Study of the Law of the Constitution, 10a. ed., Basingstoke, Macmillan Education, 1985. 
Esta revista forma parte del acervo de la Biblioteca Jurídica Virtual del Instituto de Investigaciones Jurídicas de la UNAM

que obligaba a todo ciudadano. En Inglaterra no había droit administratif o tribunaux administratifs como en Francia.

Por último, el Rule of Law implicaba que el derecho constitucional inglés - es decir las reglas que en el extranjero formaban, naturalmente, parte de un código constitucional - no fueran la fuente, sino la consecuencia de los derechos individuales, definidos y sancionados por los tribunales. Dicho de otro modo, los principios del derecho privado se extendieron, en Inglaterra, por la acción de los tribunales y del Parlamento, de manera que determinaron la posición de la Corona y de sus funcionarios; así, la Constitución fue resultado de la ley ordinaria del país (ordinary law of the land). ${ }^{49}$

Dichas ideas supusieron un salto cualitativo para la preeminencia del derecho sobre el poder público estatal. Más allá de lo general de su formulación, la idea subyacente en ellas era la de la sumisión del ejercicio del poder arbitrario del gobierno al imperio de la ley.

Sin embargo, las consideraciones formuladas por Dicey — en torno a la idea del Rule of Law-no serían del todo compartidas por algún sector de la doctrina. De hecho, autores como Jennings señalaban que Dicey concebía el Rule of Law como una regla de acción política, no como un simple principio jurídico de distribución de los poderes. El gobierno del derecho significa que las autoridades públicas no deben tener poderes amplios. En este sentido, el Rule of Law es, para Dicey, una regla de la política del partido liberal que puede ser ignorada por otros grupos políticos. Por otra parte, continúa argumentando dicho autor, en los tiempos de Dicey existieron muchos poderes discrecionales. En el siglo XVIII, por ejemplo, la mayoría de las funciones de la administración las realizaban los jueces de paz. ${ }^{50}$

Jennings concluye, frente a la tesis de Dicey, que:

si el Rule of Law significa únicamente que los poderes han de derivarse del derecho, todos los Estados civilizados lo poseen. Si significa los principios generales del gobierno democrático, es necesario mencionarlos separadamente. Si significa que el Estado tiene como única función conducir las relaciones exteriores y mantener el orden, ello no es verdad. Si significa que el Estado

49 Dicey, Albert Venn, Introduction to..., cit., nota 48, p. 203.

50 En este sentido, vease Jennings, Ivor, The Law and the Constitution, Londres, University of London Press, 1933, pp. 9 y ss. 
Esta revista forma parte del acervo de la Biblioteca Jurídica Virtual del Instituto de Investigaciones Jurídicas de la UNAM

no debe ejercer más que estas funciones, es una regla política de los whigs (el partido liberal). ${ }^{51}$

Pero al margen de dichas críticas, consideramos que el principal mérito de las tesis propuestas por Dicey fue el haber sentado las bases doctrinales de la institución jurídica del Rule of Law que, tras un largo proceso evolutivo, llegaría a constituir una pieza esencial de la columna vertebral del Common Law.

De hecho, las ideas básicas del Rule of Law aportadas por Dicey perviven, hoy día, en la mayor parte de los trabajos que analizan el contenido de dicha institución, tanto en el campo del derecho como en el de la ciencia política. ${ }^{52}$ En este sentido, podríamos señalar, a título de ejemplo, el trabajo del profesor Tamanaha titulado On the Rule of Law: History, Politics, Theory. Para dicho autor, es posible identificar dentro de la noción del Rule of Law tres ideas que, aunque estrechamente conectadas, giran en torno a situaciones distintas. En primer lugar, la idea de un gobierno sometido o limitado por la ley, en segundo lugar, la idea de la legalidad formal y, por último, la idea que denomina Rule of Law, not men. ${ }^{53}$

A pesar de lo omnicomprensivas que pudieran parecer las tres ideas propuestas por el profesor Tamanaha - inspiradas en las tesis e ideas propuestas por Dicey_-, es preciso señalar que no existe, dentro de la doctrina actual, una postura unánime en cuanto al significado, alcance y contenido de la institución jurídica del Rule of Law. Por el contrario, lo que coexisten en el plano doctrinal son distintas aproximaciones teóricas que tratan de determinar lo que dicha institución significa, implica y comprende.

$\mathrm{Al}$ análisis de estas formulaciones teóricas estará dirigido el apartado siguiente de nuestro trabajo.

\section{El Rule of Law formal y el Rule of Law material}

En el seno de la tradición jurídica del Common Law es posible identificar, en efecto, un gran número de nociones y aproximaciones teóricas

51 Ibidem, p. 291.

52 Sobre el tema, véase Stapleton, Julia, "Dicey and his Legacy", History of Political Thought, núm. 2, 1995, vol. 16, pp. 234 y ss.

53 Tamanaha, Brian, On the Rule..., cit., nota 40, pp. 114 y ss.

D.R.C 2013. UNAM, Instituto de Investigaciones Jurídicas,

Boletín Mexicano de Derecho Comparado, núm. 137, pp. 713-746. 
Esta revista forma parte del acervo de la Biblioteca Jurídica Virtual del Instituto de Investigaciones Jurídicas de la UNAM

que han sido elaboradas con el objeto de determinar tanto el alcance y contenido de la institución jurídica del Rule of Law como las implicaciones que dicha institución tendría a la luz de la sumisión del poder público al derecho.

A pesar de estar orientadas por un fin común, es decir, el estudio del imperio de la ley, resulta necesario señalar que no existe, entre dichas construcciones teóricas, una postura unánime a la hora de determinar cuál es el contenido de la institución jurídica del Rule of Law. La proliferación de tantas aproximaciones teóricas, y el hecho de que sean éstas tan distintas entre sí, han venido a añadir más confusión si cabe en la doctrina. ${ }^{54}$

Ante dicha situación, algunos autores han optado por colocar toda esta amplia gama de formulaciones teóricas, para un mejor estudio, dentro de dos grandes categorías de Rule of Law: ${ }^{55}$

De acuerdo con la primera, el objetivo primordial del Rule of Law sería el de establecer las condiciones necesarias para garantizar el desarrollo humano en toda la extensión de la palabra. Dentro de esta categoría, podríamos ubicar la Declaración adoptada por la Comisión Internacional de Juristas en Nueva Delhi, el 10 de enero de 1959, en la que se manifestaba:

The function of the legislature in a free society under the Rule of Law is to create and maintain the conditions which will uphold the dignity of man as an individual. This would include recognition of civil and political rights as well as the establishment of the social, economic, educational and cultural conditions, which the committee deemed essential to the full development of the individual's personality. ${ }^{56}$

54 En este sentido, consideramos pertinente señalar que la ausencia de unanimidad entre estas aproximaciones teóricas no implica, necesariamente, que se excluyan entre sí, pues al margen de que sus postulados puedan resultar distintos, la visión del Rule of Law que proporcionan podría ser complementaria, toda vez que dichas aproximaciones darían una respuesta distinta para una situación también diferente. Sobre el tema, véase Barber, Nicholas, "Must Legalistic Conceptions of the Rule of Law have a social dimension?", Ratio furis, núm. 4, 2004, p. 475.

55 De acuerdo con Barber "a line can be drawn between those conceptions that focus on questions of legal procedure, structure, and the formulation of laws, and, alternatively, those which include social and political rights at their core". En este sentido, ibidem, p. 475.

56 http://wrere.icj.org/article.php3?id_article=3088Eंid_rubrique $=11$ Elang=en (consultada el 18 de julio de 2012). 
Esta revista forma parte del acervo de la Biblioteca Jurídica Virtual del Instituto de Investigaciones Jurídicas de la UNAM

En efecto, a la luz del razonamiento aportado por la Comisión Internacional de Juristas, el principio del Rule of Law entrañaría, además del reconocimiento de derechos civiles y políticos, toda una serie de requisitos económicos, sociales y culturales que serían esenciales para el pleno desarrollo de la personalidad del individuo en cuanto tal. En este sentido, nos ubicaríamos ante una posición de márgenes muy amplios.

De acuerdo con la segunda formulación, antes anunciada, encontramos autores que defienden una concepción más modesta del Rule of Law. De acuerdo con sus postulados, el objetivo primordial de dicha institución sería el de limitar el ejercicio arbitrario del poder público, del tal forma que todas las acciones de la autoridad puedan ser previstas por los gobernados.

En este sentido, Hayek señala que el Rule of Law:

...means that government in all its actions is bound by rules fixed and announced beforehand - rules which make it possible to foresee with fair certainty how the authority will use its coercive powers in given circumstances, and to plan one's individual affairs on the basis of this knowledge. ${ }^{57}$

En esta misma línea, Raz manifiesta que el Rule of Law significa literalmente el imperio de la ley, lo que quiere decir, en su más amplia expresión, que la conducta de los individuos está sometida y regulada por la ley. ${ }^{58}$

Ahora bien, para la doctrina anglosajona estas dos grandes categorías constituirían los puntos extremos de la lucha por determinar cuál es el alcance y contenido de la institución jurídica del Rule of Law. La tensión dialéctica existente entre estos polos opuestos ha sido calificada, dentro del ámbito doctrinal, como thin versus thick o, lo que es lo mismo, formal frente a material o sustancial..$^{59}$

57 Hayek, Friedrich, The Road to Serfdom, London, Routledge, 2001, p. 75.

58 Raz, Joseph, The Authority of Law: Essays on Law and Morality, Oxford, Clarendon Press, 1997, p. 212.

59 La distinción entre Rule of Law formal y material sería la más común dentro de la doctrina, no obstante autores, como Fallon, distinguen entre Rule of Law historicista, formalista y legalista. Para un estudio al respecto, Fallon, Richard, "The Rule of Law as a Concept in Constitutional Discourse", Columbia Law Review, núm. 1, vol. 97, 1997, pp. 5 y ss. 
Esta revista forma parte del acervo de la Biblioteca Jurídica Virtual del Instituto de Investigaciones Jurídicas de la UNAM

Desde esta perspectiva, tal como sucede con el principio del Estado de derecho, será posible distinguir, dentro del análisis de la institución jurídica del Rule of Law, una categoría formal frente a otra material.

Para autores como Paul Craig, las teorías formales del Rule of Law son aquellas que centran toda su atención en los aspectos formales de la ley, es decir, en cómo la norma es creada y en sus atributos esenciales (generalidad, claridad, irretroactividad, etcétera); esto es, atienden a que la ley sea suficientemente clara para poder guiar la conducta de los individuos, pero no prejuzgan su contenido. Las teorías sustanciales, continúa argumentando dicho autor, son aquellas que ponen el acento en el contenido de la norma que, además de los elementos formales, debe responder a determinados principios como la justicia y la moral. ${ }^{60}$

A partir de esta dicotomía, el profesor Tamanaha ha elaborado una serie de definiciones alternativas del Rule of Law que van pasando, progresivamente, de lo formal a lo material. Estas formulaciones teóricas son presentadas por dicho autor, de forma esquemática, en el siguiente cuadro: ${ }^{61}$

FORMAL VERSIONS:

$\begin{array}{llll}\text { FORMAL } & \text { 1. Rule-by-Law } & \text { 2. Formal Legality } & \begin{array}{l}\text { 3. Democracy+ } \\ \text { Legality }\end{array} \\ \text { VERSIONS: } & \begin{array}{l}\text {-law as instrument } \\ \text { of government } \\ \text { action }\end{array} & \begin{array}{l}\text {-general, } \\ \text { prospective, clear, } \\ \text { certain }\end{array} & \begin{array}{l}\text {-consent } \\ \text { determines content } \\ \text { of law }\end{array} \\ \text { SUBSTANTIVE } & \text { 4. Individual } & \begin{array}{l}\text { 5. Rigth of Dignity } \\ \text { and/or fustice }\end{array} & \begin{array}{l}\text { 6. Social Welfare } \\ \text { VERSIONS: }\end{array} \\ & \begin{array}{l}\text { Rights } \\ \text {-property, }\end{array} & & \text {-substantive } \\ & \text { contract, privacy, } & & \begin{array}{l}\text { equality, welfare, } \\ \text { preservation of } \\ \text { autonomy }\end{array} \\ & & & \text { community }\end{array}$

\section{ALTERNATIVE RULE OF LAW FORMULATIONS}

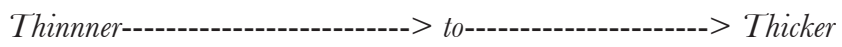

60 Craig, Paul, "Formal and Substantive Conceptions of the Rule of Law: An Analytical Framework", Public Law, 1997, p. 473.

61 Tamanaha, Brian, On the Rule..., cit., nota 40, p. 91. De acuerdo con el esquema propuesto, las tres primeras definiciones corresponderían a la categoría formal del Rule of Law, mientras que las tres últimas formarían parte de la categoría material o sustancial de dicha institución. 
Esta revista forma parte del acervo de la Biblioteca Jurídica Virtual del Instituto de Investigaciones Jurídicas de la UNAM

Para la elaboración de este mapa conceptual, el autor parte de las aproximaciones teóricas al Rule of Law que demandan menos requisitos dentro de su contenido. A la luz de este esquema, cada una de las formulaciones iría incorporando los principales elementos de la definición que le antecede, y así sucesiva y acumulativamente. ${ }^{62}$

De acuerdo con la versión más extrema del Rule of Law en su vertiente formal, que el profesor Tamanaha ha denominado Rule by Law, ${ }^{63}$ toda actuación del gobierno tiene que ser regulada y debe estar autorizada por la ley. Al conocer de antemano cuáles son las competencias que la ley le atribuye a la autoridad y en qué supuestos podrá ésta hacer uso de sus facultades coercitivas, el ciudadano podrá organizar su vida. Desde esta perspectiva, reconoce Hayek, ${ }^{64}$ el ejercicio arbitrario del poder del Estado se encontrará limitado.

Por su parte, la versión sustancial del Rule of Law más difundida, como asegura el profesor Tamanaha, ha sido aquella que ha incorporado en su contenido los derechos individuales. ${ }^{65}$ Entre los autores que defienden esta concepción, podríamos destacar a Dworkin ${ }^{66}$ quien, al contrastar la versión sustancial del Rule of Law con la formal (the rule book conception), señala que:

I shall call the second conception of the Rule of Law the "rights" conception. It is in several ways more ambitious than the rule-book conception. The Rule of Law on this conception is the ideal of rule by an accurate public concep-

62 En este sentido, la versión material del Rule of Law que incorpora el derecho a la dignidad y a la justicia (punto número 5 del mapa conceptual), exigiría de la norma los requisitos formales que están presentes dentro de las cuatro propuestas teóricas que le anteceden.

63 Tamanaha, Brian, On the Rule..., cit., nota 40, p. 92.

64 Hayek, Friedrich, The Road to..., cit., nota 57, p. 75.

65 Tamanaha, Brian, On the Rule..., cit., nota 40, pp. 91 y 102.

66 No obstante, existen otros autores que comparten una concepción similar del Rule of Law. En este sentido véase Barnett, Randy, "Unenumerated constitutional rights and the Rule of Law", Harvard Fournal of Law and Public Policy, núm. 3, 1991, vol. 14, pp. 615644; Epstein, Richard, Takings: Private Property and the Power of Eminent Domain, Cambridge, Harvard University Press, 1985, pp. 161-306; Michelman, Frank, "Law's Republic", The Yale Law Fournal, núm. 7, 1988, vol. 97, pp. 1493-1531; Weinreb, Lloyd, Natural Law and Fustice, Cambridge, Harvard University Press, 1987, p. 320. A efectos de este trabajo, tomaremos como referencia la tesis propuesta por Dworkin ya que, como antes adelantábamos, de entre todas ellas ha sido una de las que más difusión ha alcanzado.

D.R.C 2013. UNAM, Instituto de Investigaciones Jurídicas,

Boletín Mexicano de Derecho Comparado, núm. 137, pp. 713-746. 
Esta revista forma parte del acervo de la Biblioteca Jurídica Virtual del Instituto de Investigaciones Jurídicas de la UNAM

tion of individual rights. It does not distinguish, as the rule book conception does, between the Rule of Law and substantive justice; on the contrary it requires, as a part of the ideal of law, that the rules in the rule book capture and enforce moral rights. ${ }^{67}$

De acuerdo con Dworkin, las prerrogativas que posee el individuo - para con sus semejantes y frente a la autoridad — no son una concesión del derecho positivo, sino que constituyen una parte sustancial de él. Por lo tanto, los derechos individuales serían preexistentes al ordenamiento jurídico positivo. De este modo, el principio del Rule of Law sustancialmente concebido por dicho autor simbolizará un ideal conforme al cual las normas encargadas de limitar el ejercicio del poder público se encuentran fundamentadas sobre el reconocimiento de los derechos individuales. ${ }^{68}$

En suma, tras haber recorrido esta extensa gama de formulaciones teóricas, debemos recordar —como señalábamos en la introducción de este trabajo- que, a pesar de que usualmente suele considerarse al Rule of Law como un sinónimo del Estado de derecho, lo cierto es que entre ambas instituciones jurídicas existen apreciables diferencias tanto de forma como de fondo.

\section{ESTADO DE DERECHO, RULE OF LAW Y LA DIFERENCIA ENTRE LOS MODELOS CLÁSICOS}

Dentro de las tradiciones jurídicas continental y del Common Law, el Estado de derecho y el Rule of Law, respectivamente, representan los modelos clásicos a través de los cuales la idea de la sumisión del poder público al derecho ha sido expresada. A pesar de que ambas instituciones girarían en torno a una misma idea, esto es, la del imperio de la ley, es posible percibir entre ellas diferencias sustanciales.

En primer lugar, el hecho de que el Rule of Law y el Estado de derecho pertenezcan a tradiciones jurídicas distintas implica que el modo de razo-

67 Dworkin, Ronald, "Political Judges and the Rule of Law", Proceedings of the British Academy, 1978, vol. 64, pp. 259-262.

68 Véase Dworkin, Ronald, A Matter of Principle, Oxford, Clarendon Press, 1986, pp. 11 y 12. Para una crítica a la teoría desarrollada por Dworkin en torno al contenido material del Rule of Law, véase Radin, Margaret, "Reconsidering the Rule of Law", Boston University Law Review, núm. 4, vol. 69, 1989, p. 787.

D.R.C 2013. UNAM, Instituto de Investigaciones Jurídicas, Boletín Mexicano de Derecho Comparado, núm. 137, pp. 713-746. 
Esta revista forma parte del acervo de la Biblioteca Jurídica Virtual del Instituto de Investigaciones Jurídicas de la UNAM

nar sea diferente. Desde esta perspectiva, para el Rule of Law se presupone la existencia de un gobierno limitado, y el derecho es entendido como Common Law; por su parte, para el Estado de derecho o Rechtsstaat se presupone el Estado y su soberanía. Por lo que se refiere al Common Law, resulta importante destacar su forma y tipo de razonamiento jurídico - y sobre todo judicial—, más que sus reglas y principios de derecho material. ${ }^{69} \mathrm{La}$ forma y el tipo de razonamiento del Common Law siempre han sido importantes para entender el Rule of Law, pues ya Dicey, en una de sus famosas definiciones, escribía que una de sus características era que los principios de la Constitución inglesa son resultado de decisiones judiciales sobre los derechos de las personas particulares en los litigios, mientras que en las Constituciones continentales —en virtud del principio de legalidad - sucedía al contrario. ${ }^{70}$

En segundo lugar, el Rule of Law tendría una concepción más pluralista del derecho, que comprendería el Common Law - del cual es producto-, la jurisprudencia, las leyes escritas, los principios de justicia natural, otros aspectos del derecho natural y la equidad. ${ }^{71}$ El Estado de derecho, por su parte, identificaría derecho con ley escrita y haría hincapié en los códigos y en el principio de legalidad. Desde el punto de vista del Common Law, la idea del government of laws, not of men no equivaldría a la concepción continental del principio de legalidad, debido a que dicha idea no haría referencia a un gobierno impersonal de leyes abstractas, sino, más bien, a la posibilidad de llevar al gobierno ante un tribunal de justicia. ${ }^{72}$

En tercer lugar, el Rule of Law no sería un concepto técnico jurídico, sino una noción general de que el ejercicio del gobierno debe ser conforme a derecho. Por otra parte, mientras que el Estado de derecho estaría basado únicamente en la observancia de la ley por jueces y funcionarios, los cimientos del edificio del Rule of Law inglés serían, aparte de las courts of law (que son tribunales ordinarios de justicia), los tribunals (que no lo son), las public inquiries, el Parlamento, la policía y la prensa. Desde esta perspectiva, al ir más allá del ejercicio del poder político, la sumisión del

69 Pereira Menaut, Carlos, Rule of Law..., cit., nota 12, p. 43.

$70 \mathrm{Al}$ respecto, véase Dicey, Albert Venn, Introduction to..., cit., nota 48, pp. 200 y ss.

71 Sobre el tema véase Morineau, Marta, Una introducción al Common Law, México, UNAM, Instituto de Investigaciones Jurídicas, 2001, pp. 23 y ss.

72 Pereira Menaut, Carlos, Rule of Law..., cit., nota 12, p. 45.

D.R.C 2013. UNAM, Instituto de Investigaciones Jurídicas, Boletín Mexicano de Derecho Comparado, núm. 137, pp. 713-746. 
Esta revista forma parte del acervo de la Biblioteca Jurídica Virtual del Instituto de Investigaciones Jurídicas de la UNAM

poder al derecho expresada a través del Rule of Law sería considerablemente más amplia que la del Estado de derecho.

En cuarto término, para el Rule of Law la sumisión del poder al derecho sería judicialista y, en este sentido, más personal; en el Estado de derecho sería, teóricamente, legalista, basándose más en el imperio de la ley escrita - concebida con posterioridad a la Revolución Francesa como manifestación política de la voluntad general-y en el principio de legalidad que, al ser más abstracto, produce más impersonalidad. ${ }^{73}$

En quinto lugar, el Rule of Law tendría un contenido de derechos innatos, considerados anteriores a la potestad política. ${ }^{74}$ Por su parte, el $R e^{-}$ chsstaat o Estado de derecho concibe los derechos como posteriores al Estado y su legislación. Del mismo modo, para el Rechsstaat las limitaciones que los derechos implican para el poder son autolimitaciones que el Estado acepta; para el Rule of Law, aquéllas son extrínsecas y proceden de un derecho natural superior a la potestad política, o de un derecho histórico anterior, de los cuales el poder político no puede disponer libremente.

En sexto término, y desde un determinado punto de vista, el Estado de derecho podría ser considerado como una actuación, a menudo positiva, del Estado, por eso se puede hablar tanto del Estado de derecho como del Estado social y democrático de derecho. ${ }^{75}$ Por su parte, el Rule of Law pone énfasis en la sumisión de la potestad política al derecho, por lo que no tendría sentido una denominación como social and democratic Rule of Law, sino un gobierno que, aparte de someterse al Rule of Law, ponga en práctica el Welfare State. ${ }^{76}$

Finalmente, debemos señalar que, al margen de que ambas instituciones jurídicas admitan una distinción entre aproximaciones formales y materiales ${ }^{77}$ el contenido de ambas se evaluará con parámetros distintos. En este sentido, podríamos destacar, por ejemplo, el de los cauces nomo-

\section{Ibidem, p. 51.}

74 Derechos de carácter esencialmente consuetudinario, sin embargo, muchos de ellos quedarían plasmados por escrito en 1215 con la Magna Carta, también conocida como la Gran Carta de las Libertades Inglesas. Para un estudio en profundidad sobre este documento, véase Holt, James, Magna Carta, Cambridge, Cambridge University Press, 1992, pp. 441 y ss.

$75 \mathrm{Al}$ respecto véase Díaz, Elías, Estado de derecho..., cit., nota 31, pp. 44 y ss.

76 Pereira Menaut, Carlos, Rule of Law..., cit., nota 12, p. 56.

77 En este sentido, véanse Craig, Paul, "Formal and Substantive...", cit., nota 60, p. 473; Ferrajoli, Luigi, "Pasado y futuro...", cit., nota 35, p. 187. 
Esta revista forma parte del acervo de la Biblioteca Jurídica Virtual del Instituto de Investigaciones Jurídicas de la UNAM

genéticos contemplados en el seno de ambas tradiciones jurídicas. Es decir, mientras que en la tradición jurídica del Common Law el juez, en virtud del judge-made-law, es un auténtico creador de normas jurídicas, dentro de la tradición jurídica continental una actuación similar por parte del juez sería contraria al principio de legalidad. Dicha circunstancia determina, por ejemplo, que la noción del derecho, al que el poder debe estar sometido, sea distinta desde un punto de vista anglosajón que desde otro continental.

Una vez determinadas las diferencias existentes entre el Estado de derecho y el Rule of Law, retomaremos, a continuación, las dos interrogantes que planteábamos en la introducción del presente artículo: ¿sería posible extrapolar tanto el Estado de derecho como el Rule of Law al ámbito internacional - tal como han sido aplicados en el plano interno- con el objeto de subrayar la sumisión del poder público al derecho? De ser así, ¿tendrían el mismo significado y poseerían los mismos elementos que a la luz del orden jurídico estatal interno?

\section{SU EXPANSIÓN AL ÁMBITO INTERNACIONAL}

Es un hecho notorio que la preocupación por promover la sumisión del poder público al derecho y a la legalidad ha trascendido las fronteras internas. Esta afirmación es corroborada, por ejemplo, en la práctica internacional de la Organización de las Naciones Unidas. Ya en el Informe del Milenio - Nosotros los pueblos: la función de las Naciones Unidas en el siglo $X X I$ - el Secretario General de dicha Organización atribuía a la promoción del Estado de derecho una buena parte del progreso social alcanzado en el último milenio. ${ }^{78}$ Además, la Asamblea General reconocía, en la $D e$ claración del Milenio, la necesidad de promover dicho principio, no sólo en los asuntos internos sino también en los internacionales. ${ }^{79}$

Para algunos autores, entre los que destaca el profesor Koskenniemi, el germen de la aplicación de este principio a las relaciones interestatales, en el seno de la sociedad internacional, podría remontarse hasta mediados

78 Parágrafo 326 del documento A/54/2000, de 27 de marzo de 2000.

79 En particular, véase el parágrafo 9 del documento A/RES/55/2, de 8 de septiembre de 2000 . 
Esta revista forma parte del acervo de la Biblioteca Jurídica Virtual del Instituto de Investigaciones Jurídicas de la UNAM www.juridicas.unam.mx

http://biblio.juridicas.unam.mx

del siglo XVIII. ${ }^{80}$ Sin embargo, no sería sino hasta hace escasos años que el análisis de la sumisión del poder público al derecho, desde un punto de vista estrictamente internacional, comenzaría a tomar impulso convirtiéndose, por otro lado, en un tema recurrente de estudio para la doctrina. ${ }^{81}$

80 En efecto, desde 1758, año en que Emmerich de Vattel publicara su obra titulada Droit des gens ou principes de la loi naturelle appliqués à la conduite et aux affaires des nations et des souverains, los juristas que se han encargado de estudiar y analizar las distintas materias que conforman la disciplina internacional han contemplado la posibilidad de extender la aplicación de los principios liberales de la Ilustración y su corolario lógico, el Estado de derecho, a la organización de la sociedad en el ámbito internacional, del mismo modo en que dichos principios resultan aplicables dentro del orden interno. Véase Koskenniemi, Martti, "The Politics of International Law", European Fournal of International Law, núm. 4, vol. 1, 1990, p. 4.

81 Es posible identificar, dentro de la doctrina iusinternacionalista reciente, un gran número de trabajos que analizan temas vinculados al Estado de derecho desde una perspectiva internacional. Los siguientes ejemplos representan sólo una pequeña muestra de aquellos estudios que hacen referencia expresa al término Internacional Rule of Law, al margen de que los que no lo citen textualmente analicen también dicha cuestión. En este sentido, véase Beaulac, Stephane, "An Inquiry into the International Rule of Law", European University Institute Working Papers, núm. 14, 2007, pp. 1-29; Becerra Ramírez, Manuel y González Martín, Nuria (coords.), Estado de derecho internacional, México, UNAM, Instituto de Investigaciones Jurídicas, 2012; Chesterman, Simon, "An International Rule of Law", American Fournal of Comparative Law, núm. 56, vol. 2, 2008, pp. 331-362; Christenson, Gordon, "World Civil Society and the International Rule of Law", Human Rights Law Quarterly, núm. 4, 1997, vol. 19, pp. 724-737; Goodin, Robert, "Toward an international Rule of Law: distinguishing international Law-breakers from World-be Law-makers", The fournal of Ethics, vol. 9, 2005, pp. 225-246; Jacobs, Dennis, "What is an International Rule of Law?", Harvard Fournal of Law and Public Policy, núm. 1, vol. 30, 2007, pp. 3-6; Jielong, Duan, "Statement on the Rule of Law at the National and International levels", Chinese Fournal of International Law, núm. 1, vol. 6, 2007, pp. 185-188; Köchler, Hans, "The United Nations, the International Rule of Law and terrorism", Fourteenth Centennial Lecture: Supreme Court of the Philippines \& Philippine Fudicial Academy, Manila, Department of Foreign Affairs-National Security Council-Foundation for Social Justice-National Defence College of the Philippines, 2002; Morin, Jean, "L'État de Droit: émergence d'un principe du Droit international", Recueil des Cours Académie de Droit International, t. 254, 1995, pp. 1-462; Petersmann, Ernst, "How to Promote the International Rule of Law? contributions by the World Trade Organization Appellate Review System", fournal of International Economic Law, vol. 1, 1998, pp. 25-48; Sampford, Charles, "Reconceiving the Rule of Law for a Globalizing World", en Zifcak, Spencer (coord.), Globalisation and the Rule of Law, London, Routledge, 2005, pp. 9-31; Teitel, Ruti, "The Alien tort and the Global Rule of Law", International Social Science fournal, núm. 185, vol. 57, 2005, pp. 551-560. Watts, Arthur, "The International Rule of Law", German Yearbook of International Law, vol. 36, 1993, pp. 15-45.

D.R.C 2013. UNAM, Instituto de Investigaciones Jurídicas, Boletín Mexicano de Derecho Comparado, núm. 137, pp. 713-746. 
Esta revista forma parte del acervo de la Biblioteca Jurídica Virtual del Instituto de Investigaciones Jurídicas de la UNAM

Este hecho ha dado lugar a que, de forma paralela al ámbito jurídico estatal interno, se hayan elaborado, no exentas de polémica, determinadas formulaciones teóricas que, inspiradas en el Estado de derecho y el Rule of Law, propugnarían, como veremos en el apartado siguiente del presente artículo, la sumisión del poder público al derecho en el plano internacional.

\section{Estado de derecho internacional, International Rule of Law $y$ preeminencia del derecho en derecho internacional}

Resulta frecuente encontrar referencias expresas a términos tales como "Estado de derecho internacional", International Rule of Law y Preeminencia del derecho (the Rule of Law among Nations), tanto en la doctrina como en ciertos documentos emanados de algunas organizaciones internacionales, para enunciar la sumisión del poder público al derecho en el ámbito internacional.

A pesar de que estas concepciones giran en torno a la idea general del imperio de la ley en las relaciones internacionales, debemos señalar que no existe actualmente consenso alguno en torno a su alcance y contenido.

Para algún sector de la doctrina, en este sentido, la utilización de la expresión "Estado de derecho internacional" como manifestación de la sumisión del poder público al derecho genera, al menos, cierto escepticismo. ${ }^{82}$ Para estos autores, las diferencias estructurales que existen entre el orden jurídico estatal interno y el internacional constituyen un gran obstáculo para la construcción de una teoría del Estado de derecho en el plano internacional. Dichas diferencias quedarían reflejadas, por ejemplo, en la ausencia de un poder ejecutivo, un legislativo y un judicial a nivel internacional, en la naturaleza eminentemente política de la solución de

82 Sirva como ejemplo de este sector de la doctrina, Endicott, Timothy, "The impossibility of the Rule of Law", Oxford Fournal of Legal Studies, vol. 19, 1999, pp. 1-18; Frank, Thomas, Political Questions Fudicial Answers: Does the Rule of Law apply to Foreign Affairs, New Jersey, Princeton University Press, 1992; Marmor, Andrei, "The Rule of Law and its limits", Law and Philosophy, vol. 23, 2004, pp. 1-43; Silverstein, Gordon, "Globalization and the Rule of Law: a machine that runs of itself?", International Fournal of Constitutional Law, núm. 3, vol. 1, 2003, pp. 427-445; Waldron, Jeremy, "Is the Rule of Law an Essentially Contested Concept (in Florida)?”, Law and Philosophy, núm. 2, vol. 21, 2002, pp. 137-164; Williams, S., "Indeterminacy and the Rule of Law", Oxford Fournal of Legal Studies, núm. 3, vol. 24, 2004, pp. 539-562. 
Esta revista forma parte del acervo de la Biblioteca Jurídica Virtual del Instituto de Investigaciones Jurídicas de la UNAM

las controversias internacionales y en la falta de jurisdicción contenciosa obligatoria de la Corte Internacional de Justicia.

Del mismo modo, la relación asimétrica y vertical que existe entre el Estado y sus gobernados en el plano nacional - esencial dentro de la teoría del Estado de derecho-, se configura, dentro del medio jurídico-social internacional, de una forma horizontal entre Estados soberanos ${ }^{83} \mathrm{y}$, desde esta perspectiva, como asegura Rosalyn Higgins, la concepción de un "Estado de derecho internacional" resultaría, por lo menos, complicada. ${ }^{84}$

Por nuestra parte, y desde un punto de vista estrictamente terminológico, consideramos que el empleo de la expresión "Estado de derecho Internacional" para enunciar la sumisión del poder público al derecho en el ámbito de las relaciones internacionales resultaría poco viable, toda vez que, como es sabido, dicha institución jurídica se ha nutrido de una realidad socio-jurídica sustancialmente distinta a la internacional. La teoría del Estado de derecho presupone, en este sentido, la existencia de un Estado, es decir, de una organización política estatal centralizada e institucionalizada, inexistente en el ámbito jurídico internacional.

No obstante, y al margen de lo anterior, es posible identificar - a nivel doctrinal - otra corriente de pensamiento cuyas tesis defenderían y justificarían la aplicación de la idea subyacente tanto al Rule of Law como al Estado de derecho - la sumisión del poder público al derecho- en el ámbito de las relaciones internacionales. ${ }^{85}$ Desde su particular apreciación, la vertiente internacional de dicha idea cumpliría, básicamente, con los mis-

83 Esta relación horizontal se ve reflejada, por ejemplo, dentro de la Resolución 2625 (XXV) de la Asamblea General de las Naciones Unidas, de 24 de octubre de 1970, según la cual todos los Estados gozan de igualdad soberana, tienen iguales derechos e iguales deberes y son, por igual, miembros de la comunidad internacional, pese a las diferencias de orden económico, social, político o de otra índole que pudiesen existir entre ellos.

84 Higgins, Rosalyn, "The ICJ and the Rule of Law", discurso pronunciado por la entonces Presidenta de la Corte Internacional de Justicia con fecha 11 de abril de 2007. Disponible en http://wrwr.unu.edu/events/files/2007/20070411_Higgins_speech.pdf(consultada el 20 de julio de 2012).

85 En este sentido Beaulac, Stephane, "An Inquiry into...", cit., nota 81, pp. 1-29; Christenson, Gordon, "World Civil...", cit., nota 81, pp. 724-737. Goodin, Robert, "Toward an international...", cit., nota 81, pp. 225-246; Jacobs, Dennis, "What is an...", cit., nota 81, pp. 3-6; Jielong, Duan, "Statement on...", cit., nota 81, pp. 185-188; Köchler, Hans, "The United Nations...", cit., nota 81; Petersmann, Ernst, "How to Promote...", cit., nota 81, pp. 25-48; Teitel, Ruti, "The Alien...", cit., nota 81; Watts, Arthur, "The International...", cit., nota 81, pp. 15-45.

D.R.C 2013. UNAM, Instituto de Investigaciones Jurídicas, Boletín Mexicano de Derecho Comparado, núm. 137, pp. 713-746. 
Esta revista forma parte del acervo de la Biblioteca Jurídica Virtual del Instituto de Investigaciones Jurídicas de la UNAM

mos objetivos que su contraparte interna, pero adaptando su contenido a la realidad internacional. Ahora bien, dentro de dicha corriente de pensamiento debemos distinguir a los autores que se decantan por una versión formal de la sumisión del poder público al derecho - al que denominan International Rule of Law- y los que defienden una concepción sustancial - al que hemos denominado Rule of Law among Nations o preeminencia del derecho en derecho internacional-.

Desde nuestro particular punto de vista, la preeminencia del derecho en derecho internacional (the Rule of Law among Nations) constituye una moneda de dos caras, estando, de un lado, la sumisión del poder al derecho en su aspecto formal (lo que los autores anglosajones denominan International Rule of $L a w)^{86}$ - es decir, que el derecho internacional sea creado conforme a los cauces nomogenéticos previstos en el propio ordenamiento jurídico internacional-y, del otro, la sumisión del poder de los Estados al derecho en un sentido material, esto es, orientándose su contenido por una serie de principios de rango jerárquico superior —como la protección internacional de los derechos humanos- que es, en nuestra opinión, la gran aportación de la Organización de las Naciones Unidas a la conceptualización del principio de la preeminencia del derecho en derecho internacional. ${ }^{87}$

En definitiva, y al margen de que no exista consenso alguno en torno al alcance y contenido exacto de las anteriores formulaciones teóricas, lo cierto es que, como hemos puesto de manifiesto, entre dichas concepciones existen algunas diferencias que es oportuno identificar.

$86 \mathrm{Al}$ hablar de la sumisión del poder público al derecho en el ámbito internacional, la mayor parte de los autores anglosajones defiende una concepción formal del Rule of Law, habida cuenta de que, bajo su punto de vista, explicar la naturaleza sustancial de dicha institución en atención al orden internacional supondría la elaboración de toda una teoría filosófica-social. En este sentido, véase Raz, Joseph, The authority of law: essays on law and morality, Oxford, Clarendon Press, 1997, p. 211.

87 Para un estudio detallado en torno a la contribución de la Organización de las Naciones Unidas a la promoción del principio de la Preeminencia del derecho en derecho internacional, véase Villegas Delgado, César, "La promoción del Estado de derecho en el ámbito internacional: de la internacionalización de un modelo interno a la postulación de un modelo internacional en la práctica de la Organización de las Naciones Unidas", en Becerra Ramírez, Manuel y González Martín, Nuria (coords.), Estado de derecho internacional, México, UNAM, Instituto de Investigaciones Jurídicas, 2012, pp. 1-34.

D.R.C 2013. UNAM, Instituto de Investigaciones Jurídicas,

Boletín Mexicano de Derecho Comparado, núm. 137, pp. 713-746. 
Esta revista forma parte del acervo de la Biblioteca Jurídica Virtual del Instituto de Investigaciones Jurídicas de la UNAM

\section{CONCLUSiOnes}

Al finalizar estas páginas, varias ideas pueden servir para resumir lo analizado en el presente trabajo:

A pesar de que comúnmente suele considerarse al Estado de derecho como una traducción del término anglosajón Rule of Law, lo cierto es que, al margen de que ambas concepciones giren en torno a la idea de la sumisión del poder público al derecho, dichas instituciones se han gestado y desarrollado en el seno de contextos socio-jurídicos distintos, siendo el resultado, por tanto, de experiencias históricas diferentes que se traducen en lo abstracto, sistemático y legalista del primero frente a lo concreto y judicialista del segundo.

A nivel internacional, se han venido desarrollando algunas formulaciones teóricas que, inspiradas en el Estado de derecho y el Rule of Law, propugnan la sumisión del poder público al derecho pero, esta vez, para ser aplicadas en el ámbito específico de las relaciones internacionales.

Términos tales como "Estado de derecho internacional", International Rule of Law y Preeminencia del derecho en derecho internacional (the Rule of Law among Nations) son utilizados, tanto por la doctrina como por algunas Organizaciones Internacionales, para subrayar la prevalencia y el imperio de la ley en las relaciones internacionales. No obstante, sigue sin existir consenso alguno en torno al alcance y contenido de estas formulaciones teóricas que no son, por otra parte, estrictamente similares.

Desde nuestra particular apreciación, el empleo de la expresión "Estado de derecho internacional" para enunciar la sumisión del poder público al derecho en el ámbito internacional resultaría poco viable puesto que, como es sabido, la institución jurídica del Estado de derecho se ha nutrido de una realidad socio-jurídica sustancialmente distinta a la internacional. La teoría del Estado de derecho presupone, en este sentido, la existencia de un Estado, es decir, de una organización política estatal centralizada e institucionalizada, inexistente en el ámbito jurídico internacional. Distinto es extrapolar al ámbito internacional la idea subyacente al Estado de derecho, es decir, la sumisión del poder público al imperio de la ley.

En este sentido, la doctrina anglosajona habla de International Rule of Law - que, al menos desde un punto de vista estrictamente terminológico, no presupone, como el Estado de derecho, una organización política estatal centralizada e institucionalizada - para subrayar la sumisión del poder 
Esta revista forma parte del acervo de la Biblioteca Jurídica Virtual del Instituto de Investigaciones Jurídicas de la UNAM

al derecho en su aspecto formal, es decir, que el derecho internacional sea creado conforme a los cauces nomogenéticos previstos para ello y que sus destinatarios cumplan en todo momento con la legalidad internacional.

Un paso más allá del International Rule of Law identificamos a la "preeminencia el derecho" gracias, sobre todo, a la labor de la Organización de las Naciones Unidas, noción que pone énfasis, además de los aspectos formales, en el sentido material de la sumisión del poder al derecho en las relaciones internacionales, esto es, orientándose su contenido por una serie de principios de rango jerárquico superior, siendo la protección internacional de los derechos humanos uno de sus elementos estructurales.

\section{BIBLIOGRAFÍA}

Anderson, Perry, El Estado absolutista, 6a. ed., México, Siglo XXI, 1990. BARBER, Nicholas, "Must Legalistic Conceptions of the Rule of Law have a social dimension?", Ratio Furis, núm, 4, 2004.

BARNETT, Randy, "Unenumerated constitutional rights and the Rule of Law", Harvard Fournal of Law and Public Policy, núm. 3, 1991, vol. 14.

BEaulac, Stephane, "An Inquiry into the International Rule of Law", European University Institute Working Papers, núm. 14, 2007.

BÖGKENFÖRDE, Ernst, Estudios sobre el Estado de derecho y la democracia, Madrid, Trotta, 2000.

, Ernst, Recht, staat, freiheit. studien zur rechtsphilosophie, staatstheorie und verfassungsgeschichte, suhrkamp Frankfurt am Main, Verlag, 1992.

Bracton, Henry, De Legibus et Consuetudinibus Angliae, London, Richard Tottel, 1569.

, On the Laws and Customs of England, Harvard University Press, 1968, vol. II.

CaAmaño Domínguez, Francisco, Jurisdicción y procesos constitucionales, Madrid, McGraw-Hill, 1997.

Chesterman, Simon, "An International Rule of Law", American Fournal of Comparative Law, núm. 56, vol. 2, 2008.

Chevalier, Jacques, L’État de Droit, París, Montchrestien, 1994.

Christenson, Gordon, "World Civil Society and the International Rule of Law", Human Rights Law Quarterly, núm. 4, vol. 19, 1997.

CraIG, Paul, "Formal and Substantive Conceptions of the Rule of Law: An Analytical Framework", Public Law, 1997.

D.R.C 2013. UNAM, Instituto de Investigaciones Jurídicas,

Boletín Mexicano de Derecho Comparado, núm. 137, pp. 713-746. 
Esta revista forma parte del acervo de la Biblioteca Jurídica Virtual del Instituto de Investigaciones Jurídicas de la UNAM

DíAZ, Elías, Estado de derecho y sociedad democrática, Madrid, Taurus, 1998. DiceY, Albert Venn, Introduction to the Study of the Law of the Constitution, 10a. ed., Basingstoke, Macmillan Education, 1985.

DwORKIn, Ronald, A Matter of Principle, Oxford, Clarendon Press, 1986. , "Political judges and the Rule of Law", Proceedings of the British Academy, vol. 64, 1978.

ENDICOTT, Timothy, "The impossibility of the Rule of Law", Oxford Fournal of Legal Studies, vol. 19, 1999.

EPSTEIN, Richard, Takings: Private Property and the Power of Eminent Domain, Cambridge, Harvard University Press, 1985.

FALLON, Richard, "The Rule of Law as a concept in constitutional discourse", Columbia Law Review, núm. 1, 1997, vol. 97.

FERnÁNDEZ SEGAdo, Francisco, La jurisdicción constitucional en España, Madrid, Dykinson, 1984.

Ferrajoli, Luigi, "Pasado y futuro del Estado de derecho", en CARBONELL, Miguel y Orozco, Wistano (coords.), Estado de derecho, concepto, fundamentos y democratización en América Latina, México, Siglo XXIUNAM, 2002.

Frank, Thomas, Political Questions Fudicial Answers: Does the Rule of Law apply to Foreign Affairs, New Jersey, Princeton University Press, 1992.

Fromont, Michel, "République fédérale d'Allemagne. L'État de droit", Revue de Droit Public, núm. 5, 1984.

García Pelayo, Manuel, Derecho constitucional comparado, Madrid, Alianza, 1999.

, Las transformaciones del Estado contemporáneo, Madrid, Alianza, 1996. GoODIN, Robert, "Toward an International Rule of Law: Distinguishing International Law-Breakers from World-Be Law-Makers", The fournal of Ethics, vol. 9, 2005.

HayeK, Friedrich, The Road to Serfdom, London, Routledge, 2001.

Heuschling, Luc, État de Droit, Rechtsstaat, Rule of Law, París, Dalloz, 2002.

HigGins, Rosalyn, "The ICJ and the Rule of Law", discurso pronunciado por la entonces Presidenta de la Corte Internacional de Justicia, 11 de abril de 2007, http://wrwre.unu.edu/events/files/2007/20070411_Higgins_speech.pdf

Hinton, R, "English Constitutional Doctrines from the Fifteenth Century to the Seventeenth: I. English Constitutional Theories from Sir John 
Esta revista forma parte del acervo de la Biblioteca Jurídica Virtual del Instituto de Investigaciones Jurídicas de la UNAM

Fortescue to Sir John Eliot", The English Historical Review, núm. 296, vol. $75,1960$.

Holt, James, Magna Carta, Cambridge, Cambridge University Press, 1992.

JACOBS, Dennis, "What is an International Rule of Law?", Harvard fournal of Law and Public Policy, núm. 1, 2007, vol. 30.

JELLINEK, Georg, Allgemeine staatslehre, Berlín, Springer, 1922.

-, System der subjektiven öffentlichen rechte, Tübingen, Verlag, 1979.

Jennings, Ivor, The Law and the Constitution, London, University of London Press, 1933.

JiElong, Duan, "Statement on the Rule of Law at the National and International Levels", Chinese Fournal of International Law, núm. 1, 2007, vol. 6.

Kelsen, Hans, Allgemeine staatslehre, Berlín, Springer, 1925.

KÖCHLER, Hans, "The United Nations, the International Rule of Law and terrorism", Fourteenth Centennial Lecture: Supreme Court of the Philippines E̊ Philippine Fudicial Academy, Manila, Department of Foreign AffairsNational Security Council, Foundation for Social Justice-National Defence College of the Philippines, 2002.

Koskenniemi, Martti, "The Politics of International Law", European Journal of International Law, núm. 4, vol. 1, 1990.

LABAND, Paul, Staatsrecht des deutschen reiches, Tübingen, J. C. B. Mhor, 1901, t. IV.

LOGKE, John, Segundo tratado sobre el gobierno civil: un ensayo acerca del verdadero origen, alcance y fin del gobierno civil, Madrid, Alianza, 2004.

Lucas Verdú, Pablo, La lucha por el Estado de derecho, Bolonia, Real Colegio de España, 1975.

Maitland, Frederic, The Constitutional History of England, Cambridge, Cambridge University Press, 1908.

MARMOR, Andrei, "The Rule of Law and its Limits", Law and Philosophy, vol. 23, 2004.

MAUS, Ingeborg, "Entwicklung und dem funktionswandel der theorie des bürgerlichen rechtsstaates", en TOHIDIPUR (coord.), Der Bürgerlichen Rechtsstaat, Frankfurt, Suhrkamp, 1978.

MaYer, Otto, Deutsches verwaltungsrecht, Berlín, Humblot, 1924.

MaILWAIn, Charles, Constitucionalismo antiguo y moderno, Madrid, Centro de Estudios Políticos y Constitucionales, 1991. 
Esta revista forma parte del acervo de la Biblioteca Jurídica Virtual del Instituto de Investigaciones Jurídicas de la UNAM

Michelman, Frank, "Law's Republic", The Yale Law Fournal, núm. 7, vol. 97, 1988.

MOHL, Robert, Die deutsche polizeiwissenschaft nach den grundsätzen des rechtsstaates, Tübingen, Laupp, 1833.

Morin, Jean, 'L'État de Droit: émergence d'un principe du Droit international", Recueil des Cours Académie de Droit International, t. 254,1995.

MorineaU, Marta, Una introducción al Common Law, México, UNAM, Instituto de Investigaciones Jurídicas, 2001.

Pereira Menaut, Carlos, Rule of Law o Estado de derecho, Madrid, Marcial Pons, 2003.

PÉrez LuÑo, Enrique, La seguridad jurídica, 2a. ed., Barcelona, Ariel, 1994. , Derechos humanos, Estado de derecho y Constitución, 8a. ed., Madrid, Tecnos, 2003.

Petersmann, Ernst, "How to Promote the International Rule of Law? contributions by the World Trade Organization Appellate Review System", Journal of International Economic Law, vol. 1, 1998.

RADIN, Margaret, "Reconsidering the Rule of Law", Boston University Law Review, núm. 4, vol. 69, 1989.

RAZ, Joseph, The Authority of Law: Essays on Law and Morality, Oxford, Clarendon Press, 1997.

Rubio Llorente, Francisco et al., Estudios sobre jurisdicción constitucional, Madrid, McGraw-Hill, 1998.

-, "Derechos fundamentales, derechos humanos y Estado de derecho", Fundamentos: cuadernos monográficos de teoría del Estado, derecho público e historia constitucional, Oviedo, núm. 4, 2004.

SAMPFORD, Charles, "Reconceiving the Rule of Law for a Globalizing World", en ZIFCAK, Spencer (coord.), Globalisation and the Rule of Law, London, Routledge, 2005.

SCHEUNER, Ulrich, "Die neuere entwicklung des rechtsstaats", en FORSTHOFF, Rechtsstaatlichkeit und sozialstaatlichkeit, Darmstadt, Buchges, 1968. Schwartz, Pedro, "El Estado liberal", Estudios Públicos, Madrid, núm. 27, 1987.

Silverstein, Gordon, "Globalization and the Rule of Law: a machine that runs of itself?", International fournal of Constitutional Law, núm. 3, vol. 1, 2003.

STAHL, Friedrich Julius, Philosophie des rechts, Bd. II, rechts und rtaatslehere auf der grundlage christlichen weltanschauung, Hildesheim, Georg Olms, 1963. 
Esta revista forma parte del acervo de la Biblioteca Jurídica Virtual del Instituto de Investigaciones Jurídicas de la UNAM

Stapleton, Julia, "Dicey and his Legacy", History of Political Thought, núm. 2, 1995, vol. 16.

STEIn, Torsten, "Estado de derecho, poder público y legitimación desde la perspectiva alemana", Working Papers, Barcelona, Institut de Ciencies Politiques i Socials, núm. 88, 1994.

STERn, Klaus, Der rechtsstaat, Krefeld, Scherpe, 1971.

Tamanaha, Brian, On the Rule of Law: History, Politics, Theory, Cambridge, Cambridge University Press, 2006.

TeITEL, Ruti, "The Alien tort and the Global Rule of Law", International Social Science Fournal, núm. 185, vol. 57, 2005.

THOmA, Richard, "Rechtsstaatsidee und verwaltungsrechtswissenschaft", Jahrbuchs des öffentlichen Rechts der Gegenwart, Tübingen, J. C. B. Mohr, vol. 4, 1910 .

Vilegas Delgado, César, "La promoción del Estado de derecho en el ámbito internacional: de la internacionalización de un modelo interno a la postulación de un modelo internacional en la práctica de la Organización de las Naciones Unidas", en BECERRA RAMírez, Manuel y GonzÁlez MARTín, Nuria (coord.), Estado de derecho internacional, México, UNAM, Instituto de Investigaciones Jurídicas, 2012.

VolZ, Otto, Christentum und positivismus. Die grundlagen der rechts- und staatsauffassung Friedrich Fulius Stahls, Tübingen, J. C. B. Mohr, 1951.

WALDRON, Jeremy, "Is the Rule of Law an Essentially Contested Concept (in Florida)?", Law and Philosophy, núm. 2, vol. 21, 2002.

WATTS, Arthur, "The International Rule of Law", German Yearbook of International Law, vol. 36, 1993.

WeINReB, Lloyd, Natural Law and Justice, Cambridge, Harvard University Press, 1987.

Williams, S, "Indeterminacy and the Rule of Law", Oxford Fournal of Legal Studies, núm. 3, vol. 24, 2004. 